\title{
Three-factor Predictors of Marital Adjustment among Couples in Abeokuta Metropolis, Ogun State, Nigeria
}

\author{
Onabamiro, Adegbenga Ade*, Owoyele, Jimoh Wale, Elijah, Ayodele Oiukunle \\ Department of Counseling Psychology, Tal Solarin University of Education, Nigeria
}

Copyright $\bigcirc 2017$ by authors, all rights reserved. Authors agree that this article remains permanently open access under the terms of the Creative Commons Attribution License 4.0 International License

\begin{abstract}
The importance of couples understanding their personality characteristic is germane to marital bliss and adjustment. This study examined self-esteem, emotional intelligence and coping skills as predictors of marital adjustment among couples in Abeokuta metropolis. This study adopted a non-experimental ex-post facto research. It is also correlative in nature. The target population for the study comprised all the married persons in Anglican Communion Churches in Abeokuta South and North Local Government Areas in Ogun State, Nigeria. Using simple, random sampling technique a total of fifteen married persons were selected from each of the churches, making a total of three hundred and thirty, married persons (330) from Abeokuta North and South Local Government Areas, Ogun State. The study used four instruments Coping Style Questionnaire (CSQ), Self-Esteem Scale Questionnaire (SESQ), Emotional Intelligence Questionnaire (EIQ), and Marital Adjustment Questionnaire (MAQ) to generate data for the study. Frequency counts and percentage were used for presenting the data obtained from the questionnaire. Pearson Product Moment Correlation and Multiple Regression analysis were used for testing the null hypotheses. The result shows that there is no significant relationship between coping style and marital adjustment, that there is no significant relationship between self-esteem, emotional intelligence, and marital adjustment. The study recommended among others that couples should endeavor to accentuate attitude of co-operative understanding, valuing partnership, demonstrating trust, general good will towards one another and positive values in their marriage while family counselors should organize workshops, seminars and conferences whereby couples would be sensitized on causes of marital adjustment and resolution strategies for resolving marital mal-adjustment.
\end{abstract}

Keywords Self-esteem, Emotional Intelligence, Coping Skills, Marital Adjustment, Couple

\section{Introduction}

Marital adjustment is a process which is created during couples lives because it is necessary for taste conformity, person's traits recognition, behavioural rules creation and relational models formation. The importance of understanding each other personality characteristics is germane to marital bliss and adjustment. Personality is unique behaviour, thought motivation and emotion in human being and it is what makes an individual to be unique, strongly influence personal expectation, perceptions, values, attitude and even marital adjustment Tabinda [1].

Understanding the individual personality of the spouse is an ongoing process in marriage because even if two people know each other before or at the time of courtship, there is the possibility that people change during the life cycle. Marital adjustment, therefore, calls for maturity that accepts and understands growth and development in the spouse. Westman, Hamilton \& Roziner [2] find that marital adjustment starts from husband and crosses over to the wife directly. Sprecher [3] finds that relationship satisfaction negatively predicts the likelihood of relationship breakup for women in marital adjustment, but not for men. In contrast, sexual satisfaction negatively predicts the likelihood of relationship dissolution for men but not for women. Perhaps for men decreased sexual satisfaction leads to decreased relationship satisfaction, whereas for women, the reverse is the case

Bali, Rajni \& Baru [4] explained that marital adjustment is the process of modifying, adopting or altering individual and couple's pattern of behaviour and interaction to achieve maximum satisfaction in the relationship. The researchers further noted that unanimity of response between childless partners who may, however, have been tempted to idealize their relationship may also influence marital adjustment. Thus, the experience of infertility is unanticipated, and to poor women with little or no education, the failure to have any children would certainly lead to divorce or a remarriage on the part of the husband, Ahmed [5]. Research has revealed there has been a dearth of literature on coping style, self-esteem and emotional intelligence as personality of 
marital adjustment.

Even though, there are some literatures that focus on some of these variables, they do not specifically link them to marital adjustment and are limited in scope. Marital adjustment has been an issue confronting married person in Nigeria. The deficiency of marital adjustment resulted into lack of trust and others between husband and wife; children not being properly trained tended to suffer the consequences of creating social problems into the society in form of drug-abuse, cultism etc. This has also led to single parenting, re-marriages, divorce and poverty among the families. Thus, despite pertinent studies on marriages this area of marital adjustment has not been adequately examined. Based on this backdrop, this paper examined self-esteem, emotional intelligence and coping skills as predictors of marital adjustment among couples in Abeokuta metropolis.

\section{Purpose of the Study}

The main purpose of this study is to examine self-esteem, emotional intelligence and coping skills as predictors of marital adjustment among couples in Abeokuta metropolis. In specific term, the following purposes were considered:

i. To examine coping skills as a predictor influences marital adjustment of married persons;

ii. To identify relationship between self-esteem and marital adjustment of married persons;

iii. To determine the relationship between emotional intelligence and marital adjustment of married person.

\section{Hypotheses}

H01: There is no relationship between coping skills and marital adjustment

H02: There is no relationship between self-esteem and marital adjustment.

H03: There is no significant relationship between emotional intelligence and marital adjustment.

This paper is divided into five sections. Following this section is section two which examined theoretical framework and review of related empirical literature, section three focused on methodology, section four deals with data analysis while section five presents the conclusion and recommendations.

\section{Theoretical Framework}

\section{Marriage Timing Theory}

This study is anchored on Marriage Timing Theory as explained by Oppenheimer [6]. The theory is of the view that marital adjustment is subject to the timing of marriage, and it is directly related to a number of forces and factors, one of which is the time when a prospective mate with the most desired personality attributes is found. The theory states that people tend to have a prolonged search for a partner if such extended search will eventually yield in a better return of more compatible attributes and other variable benefits accruable to the searcher or the eventual union. Oppenheimer [6] thus posited that the interplay of factors and forces which influences the timing of marriage mostly leads to marital delay later (advanced) age in marriage. The above reports buttress the researcher's personal observation which not only suggests the condition of marital delay but also some pertinent issues connected to it.

Based on the foregoing, the researchers are convinced that certain issues might be associated with marital delay among many Nigerians, especially the educated ones. The researchers are therefore interested in personality variables. Personality is an all-embracing term that describes a person's consistent and unique behaviours, physical and emotional qualities as well as other traits emanating from genetic and environmental influences, Mladdi [7]. Personality variables/traits or expressions are many and diverse. Personality issues refer to matters or problems pertaining to personality attributes which have the potency of making unmarried people to or not to desire a person for marriage, Maddi [7].

\section{Review of Literature}

Seyyedeh [8] examined family functioning, marital adjustment, coping style and intimacy in middle age and young spouses. Using causal methods of research with 36 young spouses and 17 middle aged spouses, selected randomly by stratified sampling technique participating in the study, found that difference between family functioning, marital adjustment and intimacy in the two groups (middle-aged spouses and young spouses) were not significant. Another finding of the researcher was that there was no significant difference between means of dependent variables when the subjects were studied by continuation of marriage. Also evident was significant positive correlation between marital adjustment and intimacy, between family functioning and marital adjustment and between family functioning and intimacy.

Gupta \& Nafis [9] on marital adjustment, coping style and psychological well-being among working and non-working women found that working and non-working women did not differ from each other on marital adjustment as well as on psychological well-being but on few dimensions of psychological wellbeing.

Ogunsanmi [10] work investigated the influence of hours, coping style and years in employment on marital adjustment among employed married women in Ekiti state, South West Nigeria. Result of the analysis revealed that there was a significant difference in marital adjustment of the employed women with different number of hours per day. However, there was no significant difference in marital adjustment of the women based on the number of years spent in 
employment. Further analysis revealed that in relation to the hours in employment, there were significant differences in companionship and agreement on basic values of life.

Also, there were no significant differences in affectionate intimacy and accommodation of the spouses based on hours spent in employment per day. Companionship had a significant result while affectionate, intimacy, agreement on basic values of life and accommodation had no significant result based on the number of years in employment.

Manesh \& Arefi [11] explained that there was significant relation between personality traits and martial satisfaction. There is a significant correlation between attachment styles and marital satisfaction. In addition, there is a significant relationship between emotional intelligence and marital satisfaction. Personality traits impact on predicting marital satisfaction and attachment styles affect predicting marital intelligence. Finally, emotional intelligence components impact on predicting marital satisfaction.

Belanger, Schiavi, Sabourin Dugal, Ghassan \& Lusser [12] investigated relationship between self-esteem, specific coping strategies and marital adjustment and confirmed a relationship between self-esteem, specific coping strategies and marital adjustment in men and women. High self-esteem and marital adjustment are associated with the use of problem solving strategies and less' avoidance as a way of coping. Moreover, cross analysis reveal that one's feelings of self-worth ace associated with his/her spouse's marital adjustment. Hashmi, Khurshud \& Hassan [13] while exploring the relationship between marital adjustment, self-esteem, stress and depression found a highly significant relationship between adjustment, depression and stress. The findings of the results also showed that working married women have to face more problems in their marital lives as compared to non-working married women. The results further showed that highly educated working and non-working married women can perform well in their marital lives, and they are free from depression as compared to uneducated and non-working married women.

Onem, Celik, Oncu, Tankaya, Kolat, Sungu, Sevindike \& Ozer [14] also find that there was no significant difference between the groups with regard to total and subscale scores of Dyadic Adjustment Scale and GRISS total scores. Rheumatoid arthritis does not affect marital adjustment of parents, but may affect sexual functioning to some extent leading to a need for psychiatric care.

Onoyenure [15] investigated personality issues such as self-esteem as a determinant of marital adjustment among graduate students, pointing out counselling implications. The findings revealed that personality issue is a significant determinant of marital delay among male and female respondents. Also, there was no significant difference in the responses of male and female respondents. Implications of the findings were that many singles were deficient in desirable personality attributes but yet desired prospective mates with sterling personality features.

Khanbani, Aghaie \& Golparvar [16] examined the relationship between the dimensions of psychological well-being (self-acceptance/esteem, positive relationships with others, autonomy environmental mastery and personal development) aid different kinds of marriage in Isfahan city. The results showed that there was a significant relationship between the level of psychological well-being and sexuality in different marriages.

Suvarna \& Thingujam [17] examined the relationship between emotional intelligence and marital adjustment over and above personality dimensions and social desirability. The sample comprised of 60 couples. Results showed that cohesion and overall marital adjustment were related to all the subscales and overall emotional intelligence. Consensus and satisfaction subscales of marital adjustment were also related to overall and subscales of emotional intelligence except utilizing emotion subscale. Further results indicated that overall emotional intelligence's correlation with overall marital adjustment remained significant after controlling for social desirability, extraversion, agreeableness, and conscientiousness. Perception of emotion's correlation with overall marital adjustment, consensus remained significant after controlling for extraversion and openness. Managing self-emotions correlation with overall marital adjustment, satisfaction, and cohesion remained significant after controlling for social desirability, extraversion, agreeableness, conscientiousness, and neuroticism.

Shikah \& Narang [18] examined marital adjustment, emotional intelligence, menial health, frustration reactions among males and females of middle age from Delhi, India. The sample comprised of 150 males and 150 females $(n=$ 300) who were bank employees, doctors and lecturers within the age range of 40-55 years from Delhi, India. It was seen that the females showed a high level of recreational adjustment as compared to the males but the males had better group-oriented attitude than females.

Ebenuwa-Okoh [19] examined marital adjustment, emotional intelligence and co-dependency in 30 subjects - 12 male and 18 female with depression. BDI, Marital Adjustment Questionnaire and Span-Fisher Co-Dependency scale were used to assess the marital adjustment and co-dependency. However, the study could not observe any statistical significant correlation between depression and marital adjustment, depression and co-dependency and marital adjustment and co-dependency.

Bali, Dhingra \& Baru [4] examined marital adjustment of couples who were infertile, and emotionally imbalance. The sample of the study consisted of 30 childless women residing in urban areas of Jammu City and had marital duration of at least 10 years. Snowball sampling technique was adopted for sample selection. The tools used for the study were interview guide and marital adjustment questionnaire. After the analysis, it was found that out of the total respondents, 77\% had primary infertility, had suffered experiences of pregnancy wastage and $13 \%$ suffered secondary infertility. It was found that before diagnosis of the problem that $80 \%$ of the husbands had positive attitudes but after the diagnosis of 
the problem, $20 \%$ of the husbands changed their attitude from positive to negative. Childlessness had great effects on the marital adjustment of the respondents and from the entire sample group it was found that different people have different styles for spending their leisure time. Women faced both physiological as well as psychological problems due to childlessness. Ebenuwa-Okoh [20] examined the extent to which emotional expression, communication flow, financial management and work involvement predict marital adjustment among married persons in Delta Stated Nigeria. The analysis of the data generated from the respondents revealed that emotional expression, financial management, communication flow, works involvement were significant correlates and predictors of marital adjustment.

\section{Methodology}

\section{Research Design}

This study adopted non-experimental ex-post facto research. It is also correlative in nature. This design helps the researcher to examine how the variables are related and operationalized for accomplishing the research purpose.

\section{Population}

The target population for the study comprised all the married persons in Anglican Communion Churches in Abeokuta metropolis in Ogun State, Nigeria.

\section{Sample and Sampling Techniques}

Using simple random sampling technique a total of fifteen married persons were selected from each of the churches, making a total of three hundred and thirty married persons (330) tom Abeokuta North and South Local Government Areas, Ogun State. This was done by researcher and two assistant researchers.

\section{Instrumentation}

This study used four instruments, namely "Coping Skills Questionnaire (CSQ)" which measures different coping skills (confronting coping, distancing, self-control, seeking social support, escape avoidance, plan-problem-solving, positive, reappraisal, and accepting responsibility) with responses on: always (4), often (3), rarely (2) and never (1) would be used. Furthermore, "Self-Esteem Scale Questionnaire (SESQ)" consists items which offer four possible answer choices on always Strongly Agree (SA), Agree (A), Disagree (D) and Strongly Disagree (SD) would be adopted. "Emotional Intelligence Questionnaire (EIQ)" which is tailored towards measuring intra and inter-personal awareness and intra and inter-personality also adopted with the options: Strongly Agree (SA.), Agree (A), Disagree (D) and Strongly Disagree (SD). Finally, Marital Adjustment Questionnaire MAQ)" with the options: always (4), often (3), rarely (2) and never (1).

The initial draft of this questionnaire was subjected to content validity by three experts from the Department of Counselling Psychology of Tai Solarin University of Education. Each of the experts was served with the instrument and requested to rework, delete or add items as they consider appropriate. In order to ensure the reliability of the instrument, a pilot study was carried out. The instruments were administered twice within two weeks interval by two assistants on 20 married persons (male and female) from Ijebu-Ode Local Government Areas different from the study area. Thus, the test re-test reliability method was used to determine the reliability index. The data generated was correlated using Pearson Product Moment Correlation. The analysis yielded 0.79 for Coping Skills Questionnaire (CSQ), 0.88 for Self-Esteem Scale Questionnaire (SESQ), 0.89 for Emotional Intelligence Questionnaire (EIQ) and 0.75 for Marital Adjustment Questionnaire (MAQ). These reliability indexes shown that the instruments are reliable for this study.

\section{Methods of Data Analysis}

Frequency counts and percentage were used for presenting the data obtained from the questionnaires. Pearson Product Moment Correlation used for testing the null hypotheses. Thus, the null hypotheses developed for the study were tested at .05 level of significance.

\section{Data Analysis}

Hypothesis One:

$\mathrm{H} 0_{1}$ : There is no significant relationship between coping skills and marital adjustment.

Table 1. Descriptive Statistics and Correlations between the variables (Marital Adjustment and Coping Skills)

\begin{tabular}{|c|c|c|c|c|}
\hline Variables & Mean & Std. Dev & 1 & 2 \\
\hline $\begin{array}{c}\text { Marital } \\
\text { adjustment }\end{array}$ & 15.3262 & 3.65236 & 1.000 & \\
\hline Coping skills & 15.1272 & 1.57358 & .054 & \\
\hline
\end{tabular}

Table 1 shows Mean, Standard Deviation and zero order correlation between the variables. It was observed that there was no significant relationship between the independent variable (coping skills) and the dependent variable (marital adjustment) with $\mathrm{r} 0.054, \mathrm{P}>.05$ ).

On this premise, the alternative hypothesis is hereby rejected in favour of null hypotheses and researcher concludes that there is no significant relationship between coping skills and marital adjustment.

\section{Hypothesis Two:}

Ho2: There is no significant relationship between self-esteem and marital adjustment. 
Table 2. Descriptive Statistics and Correlations between the variables (Marital Adjustment and Coping skills)

\begin{tabular}{|c|c|c|c|c|}
\hline Variables & Mean & Std. Dev & 1 & 2 \\
\hline $\begin{array}{c}\text { Marital } \\
\text { adjustment }\end{array}$ & 15.3262 & 3.65236 & 1.000 & \\
\hline Coping skills & 12.4182 & 5.43609 & $.183^{* *}$ & 1.000 \\
\hline
\end{tabular}

Table 2 shows Mean, Standard Deviation and Zero order correlation between the variables. It was observed that there was significant positive relationship between the independent variables (self-esteem) and the dependent variable (marital adjustment) in the order of $(\mathrm{r}=0.183, \mathrm{P}<.05)$.

\section{Hypothesis Three}

$\mathrm{HO}_{3}$ : There is no significant relationship between emotional intelligence and marital adjustment

Table 3. Descriptive Statistics and Correlations between the variables (Marital Adjustment and Emotional Intelligence)

\begin{tabular}{|c|c|c|c|c|}
\hline Variables & Mean & Std. Dev & 1 & 2 \\
\hline $\begin{array}{c}\text { Marital } \\
\text { adjustment }\end{array}$ & 15.3262 & 3.65236 & 1.000 & \\
\hline $\begin{array}{c}\text { Emotional } \\
\text { intelligence }\end{array}$ & 23.9331 & $4,338.5$ & $.322^{* *}$ & 1.000 \\
\hline
\end{tabular}

Table 3 shows Mean, Standard Deviation and Zero order correlation between the variables. It was observed that there was significant positive relationship between the independent variables (emotional intelligence) and the dependent variable (marital adjustment) in the order of $(\mathrm{r}=0.322 \mathrm{P}<05)$. On this null hypothesis is hereby rejected in favour of alternative hypothesis and the researcher concludes that there is significant positive relationship emotional intelligence and marital adjustment.

\section{Discussion of Findings}

The study revealed that there is no significant relationship between coping skills and marital adjustment. The study, further ascertained that there is significant relationship between self-esteem, emotional intelligence and marital adjustment. These findings correlate with some previous research. For instance, Belanger, Schiavi, Sabourin, Dugal, Ghassan \& Lusser [12] in their work on coping strategies and marital adjustment, confirmed a relationship between self-esteem, specific coping strategies and marital adjustment in men and women. High self-esteem and marital adjustment are associated with the use of problem solving strategies and less avoidance as a way of coping. Onem, Celik, Oneu,Tankaya, Kolat, Sungu, Sevindik \& Ozer [14] also in their study examined marital adjustment, self-esteem and sexuality in women with rheumatoid arthritis. The result showed that there was no significant difference between the groups with regard to total and subscale scores of Dyadic Adjustment Scale and GRISS total scores. Rheumatoid arthritis does not affect marital adjustment of patients; but may affect sexual functioning to some extent leading to a need for psychiatric care. Onoyenure [15] investigated personality issues such as self-esteem as a determinant of marital adjustment among graduate students, pointing out counselling implications. The findings concluded that personality issue is a significant determinant of marital delay among male and female respondents. Also, there was no significant difference in the responses of male and female respondents. implications of the findings were that many singles were deficient in desirable personality attributes but yet desired prospective mates with sterling personality features; Khanbani, Ahaie \& Golparvar [16] examined the relationship between the dimensions of psychological well-being (self-acceptance/esteem, positive relationships with others, autonomy, environmental mastery and personal development) and different kinds of marriage in Isfahan city. The results showed that there was a significant relationship between the level of psychological well-being, and sexuality in different, marriages.

Also, Suvarna \& Thingujam [17] examined the relationship between emotional intelligence and marital adjustment over and above personality dimensions and social desirability. Result showed that cohesion and overall marital adjustment were related to all the sub-scales and overall emotional intelligence. Consensus and satisfaction subscales of marital adjustment were also related to overall and subscales of emotional intelligence except utilizing emotion subscale. Further results indicated that overall emotional intelligences correlation with overall marital adjustment remained significant after controlling for social desirability, extraversion, agreeableness, and conscientiousness. Perception of emotion's correlation with overall marital adjustment, consensus remained significant after controlling for extraversion and openness. Managing self-emotions correlation with overall marital adjustment, satisfaction, and cohesion remained significant after controlling for social desirability, extraversion, agreeableness, conscientiousness, and neuroticism.

\section{Conclusions}

Having examined self-esteem, emotional intelligence and coping skills as predictors of marital adjustment among couples in Abeokuta metropolis, it was found from the literature that marital adjustment is a process and the outcome is determined by the amount of troublesome dyadic differences, interpersonal tensions and personal anxiety, dyadic satisfaction, dyadic cohesion and consensus on matters of importance to dyadic functioning. This study concluded based on major findings of the study that there is no significant relationship between coping skills and marital adjustment. It is possible to adjust maritally, not necessarily armed with certain coping skills but with positive self-esteem and emotional intelligence, couples may not experience any itch in their marriage or they may be able to sort things out when problems arise. The study further 
ascertained that there is significant relationship between self-esteem, emotional intelligence and marital adjustment. This implies that individuals' personality needs be made stable and not troubled, the emotional intelligence too must be adequate for proper adjustment.

\section{Recommendations}

The following are recommended based on the findings of the study.

- Couples should endeavor to accentuate attitudes of co-operative, valuing partnership, demonstrating trust, general good will towards one another and positive values in their marriage.

- Clinicians in the field of counseling have to focus on the quality of marital relationship. This implies that they should put in place different intervention programs. The first stage should be purely preventive, such as marital enrichment progrmme lead to mutual understanding in marital relationship.

- Family counselor should organize workshops, seminars and conferences whereby couples would be sensitized on causes of marital maladjustment and resolution strategies for resolving marital maladjustment.

\section{REFERENCES}

[1] Tabindi, B.L. (2005). The role of husbands and wives' emotional expressivity in the marital. Sex Roles Journal, 52, 577-587. Westman, Hamilton \& Roziner [2]

[2] Sprecher, S. (2012). Sexual satisfaction in premarital relationships: Associations with satisfaction, love, commitment, and stability. The Journal of Sex Research. 39, 190-196.

[3] Bali, A., Dhingra, R., \& Baru, A. (2010). Marital adjustment and childless couples. Journal of Social Science, 24 (1). $73-$ 76.

[4] Ahmed, A. (2011). Women and fertility in Bangladesh. New Delhi: Sage Publications, 23 -8.

[5] Oppenheimer, V.K. (1988). A theory of marriage timing. The American Journal of Sociology, 94.

[6] Maadi, S.R. (2011). Personality theories - A comparative analysis $\left(4^{\text {th }}\right.$ Ed.). California: Brooks/Cole Publishing Company.

[7] Seyyedeh, F.M. (2015). The comparison of family functioning, marital adjustment and intimacy in middle aged and young spouses. International Research Journal of Applied and Basics. 3(10). 2015-2021.

[8] Gupta, G., \& Nafis, N. (2013). Does marital adjustment and psychological well-being differences in working and non-working female? The International Journal of Indian Psychology 01(03), 61 - 72.

[9] Ogunsanmi, J.O. (2014). Flours and years in empowerment marital adjustment among women: Implication for family stability. International Journal for Cross-Disciplinary Subject in Education. 5 (1), 1605 - 1608.

[10] Manesh, R. \& Arefi. M. (2015). Examining the role of personality traits, attachment styles and emotional intelligence in predicting marital satisfaction. Journal of Applied Environment Biology Sciences, 5, 270 - 275.

[11] Belanger, C, Sabourin, S., \& El-Baalbaki. G. (2012). Behavioural correlates of couples strategies in close relationships. Europe's Journal of Psychology, 8(3), 449-460.

[12] Hashmi, H.A., Khurshid, M., \&, Hassan, I. (2012). Marital adjustment; stress and depression among working and non-working married women. Internet Journal of Medical Update, 2(1), 19-26.

[13] Onem, R., Celik. S., Oneu, J., Tankaya, O., Kolat, U., Singu, B., Sevindik, S., \& Oxer, O.A. (2014). Assessment of marital adjustment and sexuality in women with rheumatoid arthritis. Arch Rheumatology Journal, 29(4), 280 - 288.

[14] Onoyenure, S.F. (2011). Personality issue as determinant of marital delay among single graduate students: Implication for counselling. Journal of Social Sciences and Public Policy, 3, 47-57.

[15] Khanbani, M., Aghaie, A., \& Golparvar, M. (2014). The relationship between dimensions of as psychological well-being and different kinds of marriage. Reef Resources Assessment and Management Technical Paper, 40(4), 327 333.

[16] Suvarna, J. \& Thingujam, N.S. (2009). Perceived emotional intelligence and marital adjustment. International Journal of Science, 2 (3), 123-148.

[17] Shikha, C., \& D. K. (201 2).Gender difference in marital adjustment, mental health and frustration reactions during middle age. Journal of Humanities and Social Science, I (3), 42-49.

[18] Ebenuwa-Okoh E.E. (2008). Personality variables as correlates of marital adjustment among married persons in Delta state of Nigeria. Educational Research and Review, 3 (8), $275-279$.

[19] Ebenuwa-Okoh, E.E. (2011). Moderators of marital adjustment among married person in Delta State: Implication for counselling practice. Journal of Psychological, 2 (1), 2935 . 